\title{
Media Type Influences Preschooler's Literacy Development: E-book versus Printed Book Reading
}

\author{
Ely Kozminsky and Revital Asher-Sadon \\ Ben-Gurion University, Beer-Sheva, Israel
}

\author{
ely@bgu.ac.il; revofer@netvision.net.il
}

\begin{abstract}
Traditionally, children's books are in a printed format and shared book reading is done with an adult. In recent years, interactive E-books have become a common medium for children's books and shared book reading is diminishing. This study compared the contribution of book format to the development of literacy in kindergarten children. We constructed an E-book, which included a story and related activities that support literacy development. The E-book was then converted to a printed format. Both formats had identical content, such as embedded graphics and literacy activities, but there were some variations due to media characteristics.

Fifty kindergarten children (5 to 6.5 years) were pair assigned to E-book reading (experimental) or printed book reading (control) condition. These pairs were matched on gender and verbal intelligence (PPVT), and they all had some experience with computers. During the first two intervention sessions children were exposed to the story, and in the next three sessions they practiced literacy activities. The E-book group listened to the story and did the activities in a digital format. The printed book group heard the same story from the experimenter, and did the same literacy activities but these were administered by the experimenter. The experimenter was instructed to be passive and just respond to children requests. The participants were tested before the intervention, after they were exposed to the story, and after the literacy practice on a battery of literacy tests: plot understanding, knowledge about print, vocabulary knowledge, phonological awareness, and orthographic awareness. Their level of involvement in the various activities was evaluated at the end of each session.

Prior to the intervention, there was no statistically significant difference between the E-book and printed groups on the literacy measures. Following the intervention, the performance of both

Material published as part of this publication, either on-line or in print, is copyrighted by the Informing Science Institute. Permission to make digital or paper copy of part or all of these works for personal or classroom use is granted without fee provided that the copies are not made or distributed for profit or commercial advantage AND that copies 1) bear this notice in full and 2) give the full citation on the first page. It is permissible to abstract these works so long as credit is given. To copy in all other cases or to republish or to post on a server or to redistribute to lists requires specific permission and payment of a fee. Contact Publisher@InformingScience.org to request redistribution permission.

groups improved on all of the literacy measures. However, performance of the printed book group improved significantly more than the E-book group on knowledge about concepts of print, understanding of the plot, and vocabulary knowledge. The duration of the intervention session was significantly longer for the E-book compared to the print condition and there was no difference among the groups in their level of in-
\end{abstract}

\section{Editor: Janice Whatley}

An earlier, shorter version of this paper was presented at the Chais conference 2013, in Raanana, Israel, and included in Y. Eshet-Alkalai, A. Caspi, S. Eden, N. Geri, Y. Yair, \& Y. Kalman (Eds.), Proceedings of the Chais Conference for Innovation in Learning Technologies 2013: Learning in the Technological Era. Raanana: The Open University of Israel. http://www.openu.ac.il/innovation/chais2013 
volvement. This study found that when controlling the experimenters' behavioral protocol, in the two media, the print format fared better than the E-book on literacy measures that benefitted from child-adult interaction.

Keywords: E-book, Printed book, Emergent literacy, Preschool

\section{Introduction}

Joint reading with young children is traditionally performed with printed books and, with an increased trend today, with interactive E-books. In the electronic format the adult's role is sometimes diminishing, substituted by programmed control and increase in multimedia features. Past comparisons of the two media regarding their effects on literacy development yielded mixed results, with small to medium effect sizes, and depending on specific features of the E-books (Zucker, Moody, \& McKenna, 2009). In addition to mixed procedures, varied populations, and literacy materials, there are also numerous differences between the compared media characteristics that are often not sufficiently detailed but generally described. In the following study the researchers attempt to list media differences that may affect media, child, and adult interactions.

The term E-book (variously, electronic book, e-book, eBook, e-Book, ebook, digital book, or even e-edition) is reserved today to a book-length digital form publication that consists of text, images, and other multimedia features. The E-book is published on a computer-based platform, nowadays on tablet-like devices in various sizes and shapes that are specifically designed for reading (e.g., electronic readers, such as Kindle, Nook, etc.) or, general purpose (e.g., iPad, Asus, Galaxy, etc.). This paper is concerned with books for young children, usually containing one story and related graphics. The books are sometimes followed by literacy activities, either in electronic or printed formats. The electronic children book is usually dubbed an "interactive E-book". For brevity, we will use the term E-book.

\section{Joint Book Reading and Literacy Growth}

Engagement during the preschool years in literacy related activities paves the way to the successful development of basic reading skills and more advanced literacy development (Sénéchal \& LeFevre, 2001; Shatil, Share, \& Levin, 2000). A major activity in the early years is joint book reading, when books are available and care givers understand their developmental potential.

Studies that focus on quality of the interaction between parents and children while reading books show that during reading parents focus primarily on images, narrative content, and unfamiliar words, occasions that provide a more natural communication setting with the child. However, they almost never engage in activities that discuss the relationship between letters and sounds or provide information about language, thus limiting the ability of the child to learn the characteristics of print (Adams, 1991; Evans \& Saint-Aubin, 2005; Hale \& Winkeckler, 1993; Justice, Skibbe, Canning, \& Lankford, 2005; Shapiro, Anderson, \& Anderson, 1997; Shatil et al., 2000; Sulzby \& Teale, 1991). Studies that combined story reading with successive activities, aimed at fostering literacy skills, supported literacy development more than just reading a story or just engaging in isolated literacy activities (Aram, 2006; Yaden et al., 2000).

Also, children learn more when they are actively involved in shared story reading, rather than being passive listeners to a story (Ewers \& Brownson, 1999; Haden, Reese, \& Fivush., 1996). Children who were active during the reading session understood more and used more words from the story, compared with passive listeners (Sénéchal, Thomas, \& Monker, 1995). 


\section{E-Books that Support Literacy Growth}

Many commercial E-books do not necessarily promote language and literacy development among young children (De Jong \& Bus, 2003; Korat \& Shamir, 2004; Shamir \& Korat, 2007). Studies have reported that the interactive nature of an E-book can sometimes distract from the story itself (De Jong \& Bus, 2002; Okolo \& Hayes, 1996; Underwood \& Underwood, 1996), because many of the incorporated interactive options divert the child's attention from the text (Korat \& Shamir, 2004). In addition, "hot" areas that are not well-matched with the story flow may divert the child's thoughts in unplanned directions, not related to the story (Labbo \& Kuhn, 2000). Therefore, the appropriate characterization of the E-book platform is essential for the success of its purpose - early literacy development.

\section{Comparing the Contribution of the E-Book and the Printed Book to Literacy Growth}

Numerous studies examined the relative contribution of the E-book and the printed book to literacy growth using a variety of methods, pitting the E-book against the printed book, against the kindergarten program, or against both. A few other studies compare different characteristics of Ebooks, as follows:

\section{A direct comparison of reading E-books relative to reading printed books}

Studies revealed similar results, following engagement in the two media, in growth of kindergarten children's phonological awareness (Wood, 2005), and word recognition (De Jong \& Bus, 2002). A lack of difference was detected in both groups in the development of writing skills, and mixed results for understanding of a story plot (De Jong \& Bus, 2004; Segers, Take, \& Verhoeven, 2004), or an advantage to the printed book over the E-book (De Jong \& Bus, 2002).

\section{A comparison between exposure to E-books and the regular kindergarten program}

Several studies found an advantage for E-books over a the regular kindergarten program on the development of knowledge about print (Shamir, Korat, \& Barbi, 2008), phonological awareness (Chera \& Wood, 2003; Korat, 2009; Shamir, 2009; Shamir et al., 2008), vocabulary (Korat, 2009; Korat \& Shamir, 2008; Shamir, 2009), understanding of the plot (Korat, 2009; Shamir, 2009; Shamir et al., 2008) and printed word recognition (Gong \& Levy, 2009; Korat, 2009; Shamir et al., 2008).

\section{Studies comparing E-book, printed book reading, and the regular kindergarten program}

The studies revealed an advantage to the E-book over the printed book on phonological awareness (Korat \& Shamir , 2004; Segal-Drori, Korat, Shamir, \& Klein, 2009), vocabulary (Korat \& Shamir, 2004; Segal-Drori et al., 2009), and knowledge about print (Korat \& Shamir, 2004; Segal-Drori et al., 2009 ). In these studies there is slight advantage for reading an E-book with an adult over reading a printed book with mediation (Korat \& Shamir, 2004, 2007; Segal-Drori et al., 2009). Also Korat and Shamir (2007) reported a similar contribution of the media and in understanding a story plot and no significant improvement in phonological awareness and word recognition following exposure to both media. 


\section{Comparisons of a static E-book to a dynamic one (with multimedia sound and animation effects)}

Verhallen, Bus, and De Jong, (2006), with kindergarteners, and Trushell and Maitland (2005), with primary students, reveal benefits to the dynamic E-book that over the static one in understanding the plot and vocabulary.

\section{The Proposed Study and Research Questions}

The different types of comparison studies listed above provided a mixed pattern of findings. Some studies point to a similar contribution of the print and the E-book media to the children literacy development. Others conclude that the traditional media still has an advantage over the electronic media, and still some point to the advantage of the electronic over traditional media. In many of these studies the media factor was not carefully detailed, nor its features carefully controlled, so results could not be attributed to specific media design considerations.

We propose to control more carefully the differences between the print and the electronic interfaces, as well as the adult's role in the engagement of the child with the media. This may shed more light on the differential role of the media on literacy development. So our research strategy is to develop an electronic interface, based in part on the above reviewed studies, that includes story reading and literacy activities. This interface was then converted to the traditional interface (reversed design), while maintaining uniformity in both media at the various stages of reading and literacy activities, except for differences that are inherent in the medium: a traditional print medium calls for a human operator to perform the readings and guide the ensuing literacy activities. In the electronic medium, the computer software drives the reading and related activities, while the human operator role is limited to mostly technical assistance. In addition, the human experimenter was asked to be passive as much as possible in the traditional medium. That is, responding to the child requests but not initiating a discussion or spontaneously pointing to objects, unless the experimental protocol indicate so.

Four questions are examined: (1) Overall, which media (print or electronic) will result in more literacy growth? (2) Which literacy skill, if any, (understanding a story plot, knowledge about print, vocabulary, phonological and orthographic awareness) will show more growth in one of the two media? (3) Are differences between media related to the child's involvement in the activities? (4) Are there differences between media in the duration of the intervention sessions?

\section{Method}

\section{Participants}

50 children, age range 5 to 6.6 years $(\mathrm{M}=5.49, \mathrm{SD}=0.38)$, were selected from 92 children in three kindergartens ( 16 from 23, 20 from 36, and 14 from 33 children, respectively) in one urban neighborhood in southern Israel, 24 males and 26 females. The selected children had normal verbal intelligence (a score of up to one standard deviation above or below average child age appropriate test (PPVT-III)). They had prior computer experience, based on a computer experience background test. Also, the selected children were not diagnosed, according to the teachers, for language impairment (e.g., Learning Disability or Attention Deficit Hyperactivity Disorder). The experimenters were six advanced undergraduate psychology female students. 


\section{Research Tools}

\section{The story used in the research}

The selected story for this research is titled in Hebrew "Pochzanim", roughly translated to "Pawkies", generally meaning cunning or sly deeds performers. The story was originally written in Polish by Grzegorz Kasdepke (no year) and translated into Hebrew and placed in an Israeli children stories site (http://sefer-li.net), devoted to translated children literature from different cultures (for noncommercial use). The story (http://sefer-li.net/nieg.pdf) is about a girl with a habit of performing mischievous acts, like throwing her father's pen to the aquarium and smearing the mirror with lipstick. That's until grandma came to take care of the naughty youngster when she was sick, and then taught her a lesson that anyone can do mischievous things (also grandmother), but they can be unpleasant to self or others.

Pawkies was selected from five stories from the stories site, based on kindergarten teachers (not participating in the experiment) recommendations. The story was edited by a language expert, and some of the original illustrations were revised (adding or modifying graphic elements) by the researchers to improve cohesion between text and story illustrations.

\section{The E-book and print environments}

The story length is 481 punctuated Hebrew words and accompanying graphics. They spread on 14 double laminated pages in the print format: 14 right justified print pages and 14 opposite pages that depict graphical illustrations that were coherent with the information on the printed page. Page size is $12 \mathrm{~cm}$ width by $21 \mathrm{~cm}$ length. The pages are bound as a book, with a front cover. In the E-book format the story and illustrations were presented on 14 screens (on a 17 inches COMPAQ VGA CRT S720, 1024X600 resolution with adjustable brightness and contrast connected to a COMPAQ d310, P4 1.7 MHz Pentium processor), with an identical page layout, Ariel font, size 26 pts., and font color black on a cream background, as in the print format. A page example, comparing the print and the E-book formats is given in Figure 1.

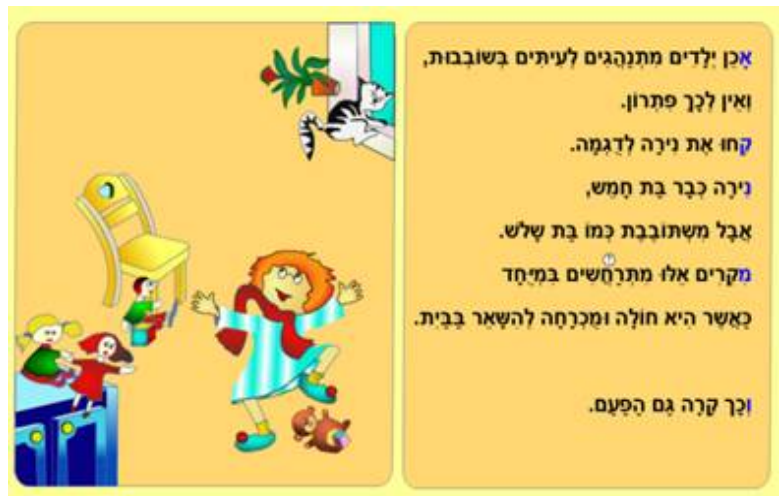

Figure 1: A page example in the print and the E-book formats during the second pass in the second session

In the first pass through the book, the child listens to the story. In the cover page the protagonist figure vocally invites the child to listen to the story. In the electronic format, this is a recording of the female researcher's voice. In the print format, the experimenter says the same words and turns the page. Then, a recording of the story is heard at a convenient $(55 \mathrm{~dB})$ volume, with adaptations, when needed, to the child and background noises, with automatic page turning in the electronic format. A moving drop-like graphics above the words indicates the location of the word 
being read. The experimenter sits passively next to the child. In the print format, the experimenter reads the story to the child at a normal volume, with similar adaptations to the child and background noises, swiping her finger from below the read words, and turning the pages.

\section{Evaluation of computer skills}

Since interaction with the electronic media involves some basic mouse manipulations, and lack of this skill may be a detriment to performance and comparison between the print and the electronic media, we developed a simple game like test to select children with some computer skill. Two puzzles were constructed by the researchers using jigsaw puzzle construction software (http://www.jigzone.com/) in order to examine two key actions of the child: clicking on and dragging puzzle pieces. Degree of computer control was measured on a 4-point scale: $1=$ not successful (not trying / not able to perform the task), 2 = barely managing (after three or more unsuccessful trials), 3 = almost successful (mistaken once or twice), $4=$ successful (no mistakes). Children, ranked 1 or 2 , or those who took more than one minute to complete the tasks, were not selected for the study.

\section{PPVT - III verbal IQ test (Dunn \& Dunn, 1997)}

Eight sets suitable for ages 2.6 to 11 years were selected. The sets were translated from English into Hebrew by the researchers. The translation was examined by two literacy development experts. Each set included twelve items of selecting the appropriate picture from a series of four that best fit a word named by the experimenter. The testing procedure and scoring were performed according to the original test instructions. The score was calculated by subtracting the number of mistakes from the numeral of the last correct item.

\section{Literacy test}

The test consists of five sub-tests that were based on existing tests (Blum, 2001; Drori, 1998; Tuval and Zeiler, 1995) and adjusted for this study (i.e., the plot of the experimental story) and administered in the following order:

(1) Plot understanding. Four questions based on a picture from the story (maximum score 4 points), and two moral inference questions about the story (maximum score 4 points).

(2) Knowledge about print. Evaluates the child's knowledge about reading direction, identifying words in text, distinguishing between text and illustration, identifying punctuations in the text and the distinction between word and letter (15 items, maximum score 30 points).

(3) Vocabulary. Examines the child's understanding of difficult words in the story (14 items, maximum score 28 points).

(4) Phonological awareness. Letter naming (11 items, maximum score 11 points), syllable omission from bi-syllabic words (eight items, maximum score 8 points) and detecting words' opening or closing sounds ( 8 items, maximum score of 8 points).

(5) Orthographic awareness. Naming one to three syllable words from the story (6 items, maximum score 12 points) and writing down these words (six items, maximum score 12 points). The above scoring was based on a 2-point scheme (0-incorrect/no answer to 1-correct answer) or a 3point scheme (0-incorrect/no answer, 1-partial answer, 2-correct answer).

The content validity and reliability of the tests have been evaluated using Cronbach Alpha. First, we examined the correlation of the sub-tests with the total literacy index, and then we examined the relatedness of each item in a sub-test to the entire sub-test. The results indicated a good internal reliability between the sub-tests in the three administrations (before, during, and at the end of 
the intervention) (.81 to .85 ). Within each sub-test, reliability ranged between 0.41 and 0.88 , with relatively low reliability in the Plot understanding sub-test, which included open response items.

\section{Involvement in the literacy tests}

In order to evaluate the degree of the child's involvement in the three literacy tests, the experimenter evaluated, at the end of each test, the child's levels of cooperation, concentration, and enjoyment during the test, on a 3-point scale, from low ("1") to high ("3") involvement. The internal reliability of the evaluations (Cronbach's Alpha) vary from $\alpha=.85$ to $\alpha=.87$. The intercorrelations between the measures vary from $r=.51$ to $r=.83$ for the two groups. Therefore, we computed a combined involvement index based on the mean of the cooperation, concentration, and enjoyment variables.

\section{Involvement in the activities}

The child was asked two questions at the end of each session: (1) How did you enjoy the activity? (2) Would you like to continue doing a similar activity? The child responded by choosing smileys, from one (very little, not at all) to three smileys (a lot, very much) for the two questions respectively. We adapted this scale from Trehearne, Healy, Williams, and Moore (2003) that applied it to evaluate children's attitude towards reading and writing. The internal reliability of evaluation scores in the five meeting was about $\alpha=.83$, but we kept the two measures separate, since the correlation between them was just $r=.42$.

\section{Procedure}

The children in each kindergarten were paired matched on gender and verbal intelligence. Then, within a pair, they were randomly assigned to an experimental group $(\mathrm{N}=25)$ exposed to the $\mathrm{E}$ book or to a control group $(\mathrm{N}=25)$ exposed to the printed book.

Eight individual bi-weekly sessions were held with each child, five intervention sessions $(2,3,5$, $6,7)$ and three evaluation sessions $(1,4,8)$. The six experimenters operated in pairs, one pair in each kindergarten. They were randomly assigned to interact with either the experimental or the control children in the intervention sessions, while the other one video recorded the session. The interacting experimenter also directed the respective evaluation sessions.

The children were called by an experimenter into the arranged experiment room. It was a side room in the kindergarten complex, separated (but not soundproofed) from the main classroom. The meetings were held during the beginning of the school day (from 0800 to about 1030), and consisted of four consecutive intervention meetings (experimental, control, experimental, control) a day in each kindergarten.

\section{Intervention sessions}

In the first intervention session, the child listened to the story read by an experimenter in the print format or listened to a recording in the E-book format, while following the print and illustrations on the pages or on the screens. The story was read at a pace of 65-68 words per minute by a trained experimenter (about 7.2 minutes for the entire story) in the print format. A recording of the female researcher, reading the story at a pace of 58-60 words per minute (about 8.2 minutes for the entire story) was used in the E-book format. In the second session, the story was first read as in the first session, and then, after an explanation and a demonstration, the child was asked to choose to listen to individual sentences on each page, by pointing to or pressing on the first letter of a sentence colored in light blue, or listen to individual marked words, by pointing to or pressing on them, and receive an explanation of the re-read word from the experimenter in the print version or a recorded explanation in the E-book version. Also, the child could listen to utterances 
of the characters in the illustrations in the E-book format, where in the print format the experimenter uttered the characters lines. In the third to the fifth sessions, the child first listened to a continuous reading of the story as in the first session, and then participated in three activities to foster literacy skills, each consisting of several rounds of play: (1) Detecting the first letter sound that matched a named picture (six rounds); (2) Detecting a word (viewed and spoken) in a segment of the displayed story (six rounds); (3) Emotionally reacting to displayed and read sentences based on the story, whether they evaluated to be sad or joyous (four rounds). The sessions lasted about 10-31 minutes each on the average, depending on the session's characteristics and format. The sessions were video recorded, and the recordings were used to evaluate session durations.

\section{Evaluation sessions}

The literacy test was administered during the evaluation sessions. The first session was held before the start of the intervention, the second, after the exposure to the book in the first two intervention sessions, and the third evaluation, after the last intervention session. The evaluation sessions lasted about 40 minutes, divided into two 20 minutes parts with a short break between them.

\section{Results}

There were no age, verbal intelligence, or computer experience with statistically significant differences among the three kindergarten classes $(F(2,47)=0.40, F(2,47)=0.60, F(2,47)=1.99$, respectively). Therefore, kindergarten classes were not used as an independent block factor in the analyses. Statistically significant differences are reported at $p<.05$.

\section{Literacy Tests}

The results of the literacy tests are presented in Table 1. We first tested whether there are statistical differences between the groups before the intervention. A two-way repeated measure Analysis of Variance (groups and times) yielded no difference between the groups before the intervention $\left(F(1,24)=1.24, \eta^{2}=.05, p=n s\right)$. Comparing the groups before the intervention on each of the five literacy indices show no significant statistical differences $(p>.05)$ : plot understanding $(t(24)$ $=0.37)$, knowledge about print $(t(24)=1.64)$, vocabulary $(t(24)=0.04)$, phonological awareness $(t(24)=1.66)$, and orthographic awareness $(t(24)=0.61)$.

In the second stage, an Analysis of Variance with repeated measurements of literacy measures, times and experimental groups was conducted. It indicated that a significant main effect was obtained for time $\left(F(2,48)=124.32, \eta^{2}=.84, p<.001\right)$. That is, there is a growth over time in the literacy indices across the study groups, as detailed in Table 1 . There was no main effect for the experimental groups $\left(F(1,24)=3.99, \eta^{2}=.14, p=n s\right)$. There was a main effect for the literacy measures $\left(F(4,96)=116.44, \eta^{2}=.83, p<.001\right)$, and literacy measures, times and experimental groups 3-way interaction $\left(F(8,192)=2.78, \eta^{2}=.10, p<.01\right)$.

In the third stage, individual Analysis of Variances for each literacy index and Bonferroni based continuation analyses were performed. For plot understanding, in addition to main effects of group $\left(F(2,46)=27.26, \eta^{2}=.54, \mathrm{p}<.001\right)$ and time $\left(F(2,46)=27.26, \eta^{2}=.54, \mathrm{p}<.001\right)$, the print condition outperformed the electronic condition in the second and the third measurement times (group by time interaction effect, $F(2,46)=3.25, \eta^{2}=.12, p<.05$ ), which is mostly due to the change from the first to the second intervention sessions. For knowledge about print, the control group significantly outperformed the experimental group $\left(F(1,23)=5.51, \eta^{2}=.19, p<.05\right)$. There was a score increase over time $\left(F(2,46)=86.66, \eta^{2}=.79, \mathrm{p}<.001\right)$, both from the first to the second and from the second to the third time measurements. There was no group by time interaction $\left(F(2,46)=0.43, \eta^{2}=.01, p=n s\right)$. Regarding vocabulary, the print control group outperformed the E-book experimental group $\left(F(1,23)=5.51, \eta^{2}=.19, p<.05\right)$. Also, there was a vo- 
cabulary increase over time beyond the study groups $\left(F(2,46)=50.84, \eta^{2}=.69, \mathrm{p}<.001\right)$ and a statistically significant time by group interaction between the first measurement the second and third $\left(F(2,46)=6.12, \eta^{2}=.21, \mathrm{p}<.01\right)$. The control improved compared with the experimental group over time. This effect is mostly due to the vocabulary differential in the third measurement between the control relatively to the experimental group $\left(t(24)=2.21, p<.05 ; D_{3}=11.43, S D_{3}=\right.$ 26.94). For phonological awareness and orthographic awareness there was significant effects of time, $\left(F(2,46)=22.63, \eta^{2}=.50, \mathrm{p}<.001\right)$ and $\left(F(2,46)=35.75, \eta^{2}=.61\right)$, respectively, but no group differences and no group by time interactions were noticed. Both indices showed a statistically significant improvement between the first to the second, and the second to the third measurements.

Table 1: Percentage means and (standard deviations) of literacy measures (Plot understanding, Knowledge about print, Vocabulary, Phonological and Orthographic awareness) before, during (after the second intervention session), and after the intervention in the E-book and the Print groups

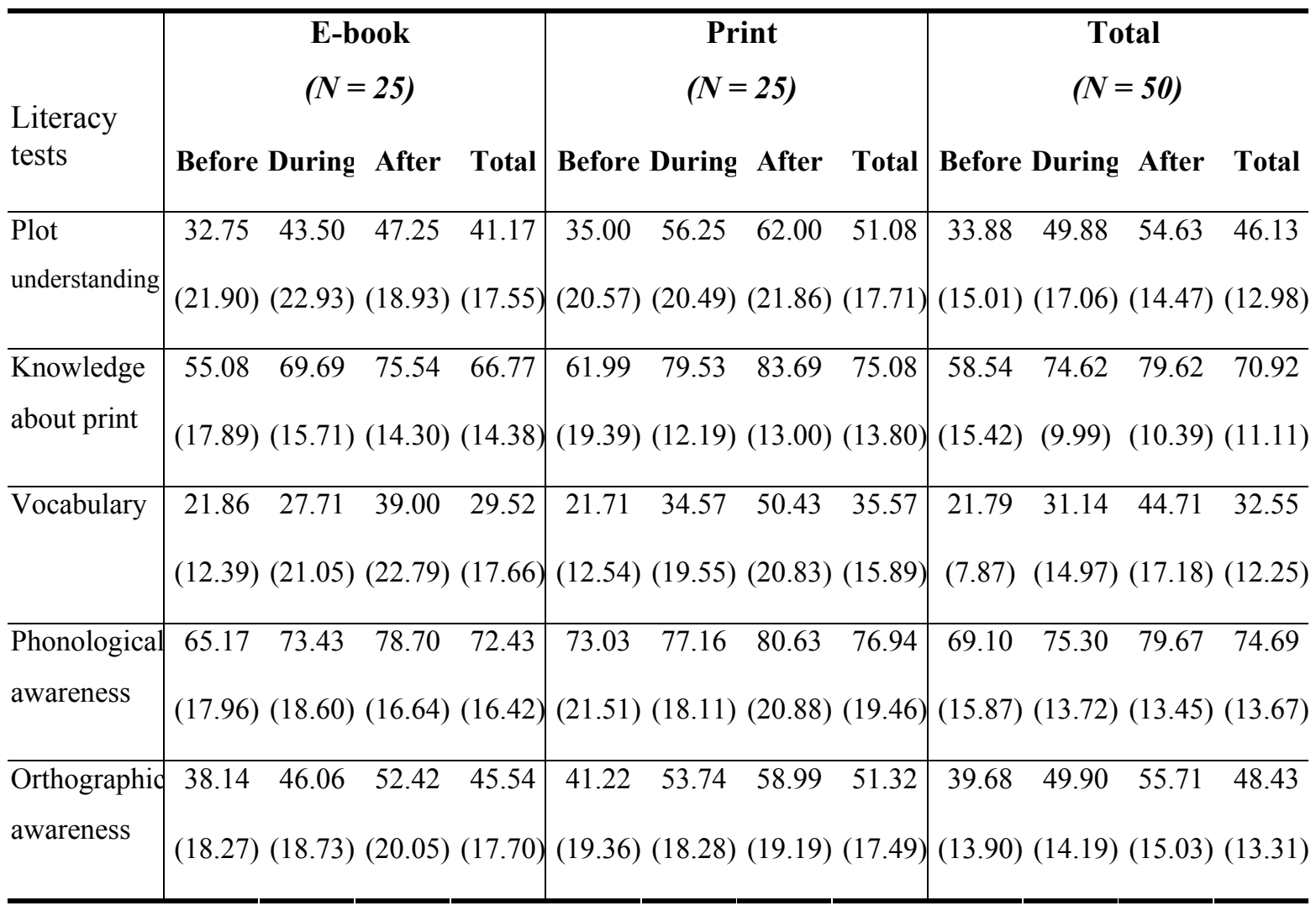

\section{Involvement in the Literacy Tests}

Test involvement was high in both groups and in the three measurements $(M=2.47, S D=.48)$. There were no differences between the groups $\left(F(1,24)=0.04, \eta^{2}=.00, p=\mathrm{ns}\right)$, test time $(F(2$, $\left.48)=.19, \eta^{2}=.01, p=n s\right)$, and no interaction between group and time $\left(F(2,48)=2.75, \eta^{2}=.10\right.$, $p=\mathrm{ns})$. 


\section{Involvement in the Activities}

Sense of involvement in the activities was high across sessions and groups in the two measures $(M=2.62, S D=.40$, enjoyment from the activities; $M=2.47, S D=.51$, a wish to continue the activities). For enjoyment from the activities, there were no differences between groups $(F(1,24)$ $\left.=2.00, \eta^{2}=.08, p=\mathrm{ns}\right)$, among test times $\left(F(4,96)=.38, \eta^{2}=.02, p=\mathrm{ns}\right)$, and no interaction between group and time $\left(F(4,96)=.51, \eta^{2}=.04, p=n s\right)$. Similarly, for wish to continue to other activities, there were no differences between groups $\left(F(1,24)=.02, \eta^{2}=.00, p=\mathrm{ns}\right)$, among test times $\left(F(4,96)=1.62, \eta^{2}=.06, p=\mathrm{ns}\right)$, and no interaction between group and time $(F(4,96)=$ $\left.0.27, \eta^{2}=.01, p=\mathrm{ns}\right)$.

\section{Intervention Duration}

The average durations of the sessions ranged between 10 and 31 minutes, with differences between groups $\left(F(1,24)=110.39, \eta^{2}=.82, p<.001\right)$, and among sessions $\left(F(4,96)=252.18, \eta^{2}\right.$ $=.91, p<.001)$ (see Table 2$)$. The electronic group was considerably slower than the print one in all sessions. The first session (just reading) was the shortest and the second session (reading with reading activities) longest (Bonferroni comparisons). The interaction between groups and sessions was also statistically significant $\left(F(4,96)=55.69, \eta^{2}=.70, p<.001\right)$. The largest difference among groups, using contrast analysis, was noted in the second session $\left(F(1,24)=10.58, \eta^{2}\right.$ $=.31, p<.001)$.

Table 2: Intervention sessions duration averages (minutes) and (standard deviations) of the electronic and the print groups $(\mathbf{N}=\mathbf{2 5})$

\begin{tabular}{l|lllll}
\hline & Electronic & Print & $\boldsymbol{d}$ & Total & $\begin{array}{l}\boldsymbol{t} \text {-test } \\
\boldsymbol{d} \boldsymbol{f}=24\end{array}$ \\
\hline $1^{\text {st }}$ Session & 14.00 & 10.32 & 3.68 & 12.60 & $18.62^{*}$ \\
& $(0)^{* *}$ & $(0.98)$ & $(0.99)$ & $(0.49)$ & \\
$2^{\text {nd }}$ Session & 31.16 & 22.92 & 8.24 & 27.04 & $7.79^{*}$ \\
& $(4.82)$ & $(2.80)$ & $(5.29)$ & $(2.92)$ & \\
$3^{\text {rd }}$ Session & 20.08 & 15.84 & 4.24 & 17.96 & $6.84^{*}$ \\
& $(1.53)$ & $(2.48)$ & $(3.10)$ & $(1.35)$ & \\
$4^{\text {th }}$ Session & 21.32 & 15.60 & 5.72 & 18.46 & $10.59^{*}$ \\
& $(2.30)$ & $(1.47)$ & $(2.70)$ & $(1.38)$ & \\
5 & $(16.20$ & 5.08 & 18.74 & $8.98^{*}$ \\
& 21.28 & $(1.76)$ & $(2.83)$ & $(1.18)$ & \\
\hline Total Session & $(1.93)$ & 16.76 & 5.39 & 18.87 & $14.48^{*}$ \\
& 21.57 & $(0.96)$ & $(1.86)$ & $(0.74)$ & \\
\hline
\end{tabular}

$* \mathrm{p}<.001 \quad * *$ Recorded session 


\section{Discussion}

The children's activities within the two media, print or electronic formats, resulted in an overall improvement in literacy scores. This improvement was slightly in favor of the print condition. Specifically, in two measures, phonological and orthographic awareness, the two groups similarly improved. While in the other three measures, plot understanding, knowledge about print, and vocabulary, the children that were exposed to the print format flourished more following the intervention compared with the children that were exposed to the electronic format.

This pattern of results is consistent with past research. Wood (2005) found no differences in phonological awareness growth between traditional print and E-book exposures. Also, for orthographic awareness growth, there were no differences between these formats (reading words: De Jong \& Bus, 2002; identifying words: Segal-Drori et al, 2009). De Jong and Bass (2002) also found that there has been no development in the ability of writing words in both groups. An advantage in phonological awareness for an E-book program was found only in a comparison to a regular Kindergarten program (Chera \& Wood, 2003; Korat, 2009; Korat \& Shamir, 2004; Shamir, 2009; Shamir et al., 2008). Apparently, code (i.e., phonological and orthographic) awareness development, fares equally in an electronic or in a print environment, where the human role is limited to supervise a drill like practice. In the current study, the adult's role was similar in the two experimental conditions, in regard to practicing code awareness skills. There was a very limited interaction between the adult experimenter and the child, as was designed by us: the experimenter in the print condition mimicked the limited feedback offered by the prerecorded messages in the electronic condition.

However, different behavior patterns are suggested for coaching higher order skills during reading and practice in the two conditions. Here, past research findings show a clear advantage for activities with the printed book over the E-book format in plot understanding, knowledge about print, and vocabulary. De Jong and Bus (2002) found that the printed book promoted plot understanding more than the E-book format, and similarly in other studies (De Jong \& Bus, 2004; Korat \& Shamir, 2007; Segers et al., 2004). Korat and Shamir (2007) reported similar vocabulary development in the two media. The advantage of the E-book format regarding knowledge about print is noticed only when the E-book format has been pitched against a regular kindergarten program (Shamir et al., 2008) or when the E-book and the printed book were compared to a regular kindergarten program (Korat \& Shamir, 2004; Segal-Drori et al., 2009). In this study, following intervention, the print condition benefitted more plot understanding, knowledge about print, and vocabulary scores compared with the electronic condition. The reason, we propose, is that the human experimenters still interact with the children during the intervention sessions. We limited this interaction by instructing the experimenters not to spontaneously initiate a discussion or pointing to objects beyond the electronic protocol. However, since children are used to the print environment and to the interaction surrounding literacy activities, they probably turned to the experimenters for explanations on difficult words, on plot turns, and indirectly about print concepts. So the experimenters responded - a clear advantage for the print condition.

There is another caveat to this study: the duration of the intervention sessions. There are few comparison studies that report actual durations. Usually, interventions are carried out in a given time slot. But what is the effective engagement during that time? In our study we discovered, that, although we asked the print experimenters to adjust their behaviors according to the electronic protocol, durations were longer in the E-book format compared to the print, in all sessions, by about 25 to 30 percent, considering the faster story reading times of the human experimenters. In the design of the experiment we pitted against the print condition, by "tying the hands" of the print experimenters (i.e., "don't initiate discussion, just respond", produce the same lines as in the E-book protocol, etc.), but it was successful both in performance and in shorter task durations. Apparently, the young children, even with some computer experience, are more versed with a 
print interface and still have more capabilities to favor the human environment for the purpose of literacy development. But the E-book is not far behind and is a viable alternative when a teacher is not readily available.

Finally, regarding levels of involvement in the tests (experimenter evaluation) and in the activities (child evaluation), the scores were high and so did not statistically differentiate between groups or times. This could be good, because both the print and the electronic conditions were appealing and led to a gratifying experience for the children (there were eight meetings). However, the scores were close to the upper limit of the measurement scale, so correlating them with literacy achievements or times was meaningless. In order to do so, we should find more sensitive measures, such as counting spontaneous distractions that will produce more variability.

\section{Limitations of the Study}

This study is a field based experiment. We strived for homogeneity. Therefore, we decided on one urban location with three kindergartens. We were able to generate 25 cohort pairs, cutting of children with low or high verbal intelligence, computer novices, and children with special needs, leaving 50 out of 92 in the sample. Therefore, some of the variability that we have omitted limits our conclusions to the sample characteristics. Also, the evaluation was repeated with the same materials, consequently some of the score increase may be due to sensitization-to-the-test effect. A third control group with no intervention could assist in establishing a base line. But the limited sample was not enough for that.

The experiment was performed in kindergartens, thus this increases its ecological validity. But real kindergartens and schools are sometimes noisy and disruptive. Since the execution of the experiment required logistics, the distribution of background noises could not be controlled. Moving to a lab or better isolating the experiment room in the kindergarten can be a solution, in further research.

\section{Conclusions}

We examined in this study the relative contributions of the print (traditional) and the electronic media to literacy development of kindergarten children. Both the print and electronic media can foster literacy skills before entering school. There was a slight advantage of exposure to print for some of the skills (understanding a story plot, knowledge about print, and vocabulary) over the electronic media. However, in the electronic media, with some initiation, the child can operate without the assistant of an adult. This is an advantage for a teacher that has to handle several dozen youngsters. Also note that the results reported here are not necessarily indicative of similar learning processes of the children in the two media. To reveal the learning processes requires a micro-analysis of the child-adult-print-computer behaviors during the engagement periods, which will be presented elsewhere.

The conclusions are also limited to the indices space that was examined. Possible lack of differences between media or advantage of one media over another one is a function of the indices examined that were derived mostly from traditional print media. Electronic media may induce additional or different behaviors than those observed in traditional media, such as spatial learning. This could lead, when measured, to different findings about literacy development than those obtained in this study. Accordingly, we recommend further research to derive metrics that characterize electronic media, and measure their effect upon the child's learning in both media. 


\section{Acknowledgement}

The research reported in this paper is based on the second author's doctoral study. We would like to thank Gal Ben-Yehudah for here helpful comments in the process of revising this paper for publication.

\section{References}

Adams, M. J. (1991). Beginning to read: Thinking and learning about print. Cambridge, MA: MIT Press.

Aram, D. (2006). The continuity in children's literacy achievements: A longitudinal perspective from kindergarten to school. First Language, 25, 259-289.

Blum, P. (2001). Syllable segmentation in the Hebrew language: Orthographic and phonological influences. MA thesis, University of Haifa. (Hebrew)

Chera, P., \& Wood, C. (2003). Animated multimedia "talking books" can promote phonological awareness in children beginning to read. Learning and Instruction, 13, 33-52.

De Jong, M. T., \& Bus, A. G. (2002). Quality of book-reading matters for emergent readers: An experiment with the same book in a regular or electronic format. Journal of Educational Psychology, 94, 145-155.

De Jong, M. T., \& Bus, A. G. (2003). How well suited are electronic books to supporting literacy? Journal of Early Childhood Literacy, 3, 147-164.

De Jong, M. T., \& Bus, A. G. (2004). The efficacy of electronic books fostering kindergarten children's emergent story understanding. Reading Research Quarterly, 39, 378-393.

Drori, D. (1998). The relationship between orthographic and phonological information processing and the phonetic method to reading acquisition. MA thesis, Tel -Aviv University. (Hebrew)

Dunn, L. M. \& Dunn, L. M. (1997). Examiner's Manual for the PPVT-III, Peabody Picture Vocabulary Test (3rd ed.). American Guidance Service, Inc. (Form IIIA and Form IIIB).

Evans, M. A., \& Saint-Aubin, J. (2005). What children are looking at during shared storybook reading: Evidence from eye movement monitoring. Psychological Science, 16, 913 - 920.

Ewers, C. A., \& Brownson, S. M. (1999). Kindergartners' vocabulary acquisition as a function of active vs. passive storybook reading, prior vocabulary, and working memory. Reading Psychology, 20, 11-20.

Gong, Z., \& Levy, B. A. (2009). Four year old children's acquisition of print knowledge during electronic storybook reading. Reading \& Writing, 22, 889-905.

Haden, C. A., Reese, E., \& Fivush, R. (1996). Mothers' extratextual comments during storybook reading: Stylistic differences over time and across texts. Discourse Processes, 21, 135-169.

Hale, C., \& Winkeckler, E. (1993). Influence of parent child interaction during reading on preschoolers' cognitive abilities. Paper presented at the biennial meeting of the Society for Research in Child Development, New Orleans, LA.

Justice, L. M., Skibbe, L., Canning, A., \& Lankford, C. (2005). Pre-schoolers, print and storybooks: An observational study using eye movement analysis. Journal of Research in Reading, 28, 229-243.

Korat, O. (2009). The effects of CD - ROM storybook reading on Israeli children early literacy as a function of age group and repeated reading. Education and Tecnology, 14, 39-53.

Korat, O., \& Shamir, A. (2004). Are electronic books for young children appropriate to support literacy development? A comparison across languages. Journal of Computer Assisted Learning, 20, 257-268.

Korat, O., \& Shamir, A. (2007). Electronic books versus adult readers: Effects on children emergent literacy as a function of social class. Journal of Computer Assistance Learning, 23, 248-259.

Korat, O., \& Shamir, A. (2008). The educational electronic book as a tool for supporting children's emergent literacy in low versus middle SES Groups. Computers \& Education, 50, 110-124. 


\section{E-book versus Printed Book Reading}

Labbo, L. D., \& Kuhn, M. R. (2000). Weaving chains of affect and cognition: A young child's understanding of CD-ROM talking books. Journal of Literacy Research, 32, 187-210.

Okolo, C., \& Hayes, R. (1996). The impact of animation in CD-ROM books on students' reading behaviours and comprehension. Paper presented at the meeting of the Council for Exceptional Children, Orlando, Florida.

Segal-Drori, O., Korat, O., Shamir, A., \& Klein, P. S. (2009). Reading e-books and printed books with and without adult instruction: Effects on emergent reading. Reading and Writing, 23, 913-930.

Segers, E., Take, L., \& Verhoeven, L. (2004). Teacher-mediated versus computer-mediated storybook reading to children in native and multicultural kindergarten classrooms. School Effectiveness and School Improvement, 15, 215-226.

Sénéchal, M. \& LeFevre, J. A. (2001). Storybook reading and parent teaching: Links to language and literacy development. New Directions for Child and Adolescent Development, 92, 39-52.

Sénéchal, M., Thomas, E., \& Monker, J. (1995). Individual differences in 4 year old children's acquisition of vocabulary during storybook reading. Journal of Educational Psychology, 87, 218-229.

Shamir, A. (2009). Processes and outcomes of joint activity with e-book for promoting kindergartener's emergent literacy. Educational Media International, 46, 81-96.

Shamir, A., \& Korat, O. (2007). Developing an educational e-book for fostering kindergarten children's emergent literacy. Computers in the Schools, 24, 125-145.

Shamir, A., Korat, O., \& Barbi, N. (2008). The effects of CD-ROM storybook reading on low SES kindergarteners' emergent literacy as a function of activity context: Paired peer tutoring versus individual use of the e-storybook. Computers \& Education, 51, 354-367.

Shapiro, J., Anderson, J., \& Anderson, A. (1997). Diversity in parental storybook reading. Early Child Development and Care, 127-128, 47-59.

Shatil, E., Share, D. C., \& Levin, I. (2000). On the contribution of kindergarten writing to grade one literacy: A longitudinal study in Hebrew. Applied Psycholinguistics, 21, 1-21.

Sulzby, E., \& Teale, W. (1991). Emergent literacy. In R. Barr, M. Kamil, P. Mosenthal \& P.D. Pearson (Eds.), Handbook of Reading Research (Vol. 2, pp.727-757). New York: Longman.

Trehearne, M. J., Healy, L. H., Williams, M. C., \& Moore, J. L (2003). Comprehensive literacy resource for kindergarten teachers. Vernon Hills, IL: ETA/Cuisenaire.

Trushell, J., \& Maitland, A. (2005). Primary pupils' recall of interactive storybooks on CD - ROM: Inconsiderate interactive features and forgetting. British Journal of Educational Technology, 36, 57-66.

Tuval, C., \& Zeiler, I. (1995). Concepts about print: A tool to evaluate emergent literacy skills. Jerusalem: Ministry of Education, Culture, and Sport. (Hebrew). (Adaptation of Clay, M. (1979). Stones: The Concepts About Print Test. Portsmouth, NH: Heinemann)

Underwood, G., \& Underwood, J. (1996). Gender differences in children's learning from interactive books? Technology and communications: Catalyst for educational change, Vol 1. In Proceedings of the Twelfth International Conference on Technology and Education, New Orleans, Grande Prairie, ICTE, Texas.

Verhallen, M. J., Bus, A. G., \& De Jong, M. T. (2006). The promise of multimedia stories for kindergarten children at risk. Journal of Educational Psychology, 98(2), 410-419.

Wood, C. (2005). Beginning readers' use of 'talking books' software can affect their reading strategies. Journal of Research in Reading, 28, $170-182$.

Yaden, D. B., Tam, A., Madrigal, P., Brassell, D., Massa, J., Altamirano, S., \& Armendariz, J. (2000). Early literacy for inner city children: The effects of reading and writing interventions in English and Spanish during preschool years. The Reading Teacher, 54, 186-189. 
Zucker, T., Moody, A., \& McKenna, M. (2009). The effects of electronic books on prekindergarten-tograde 5 students' literacy and language outcomes: A research synthesis. Journal of Educational Computing Research, 40, 47-87.

\section{Biographies}

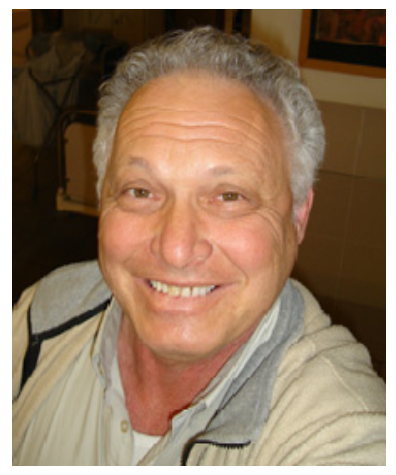

Ely Kozminsky is a faculty member at the Department of Education, Ben-Gurion University, Israel. His interests span literacy development, text comprehension, and learning and instruction with technology. Currently, he studies how graphic organizers assist learning from texts and how technology affects literacy.

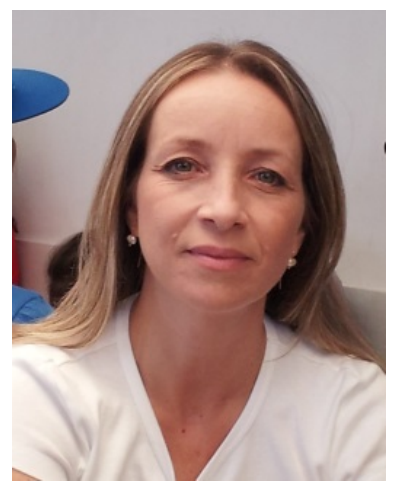

Revital Asher-Sadon is $\mathrm{PhD}$ student in the Department of Education, Ben-Gurion University, Israel. Her research interests include the use of E-book among preschool children, and the contribution of this media to foster literacy abilities of young children. The research reported in this paper is based on part of her doctoral study. 